\title{
Mandeville und die Ökonomie der Sehnsucht
}

Erhard Taverna

1 Altmann A. 34 Tage 33 Nächte: von Paris nach Berlin zu Fuss und ohne Geld. München: Fredeking \& Thaler; 2004.

2 Büscher W.

Berlin-Moskau. Hamburg: Rowohlt; 2003.

3 Schalansky J. Taschenatlas der abgelegenen Inseln. Frankfurt: Fischer

Taschenbuchverlag; 2012.

«Robinson Fieber» steht auf dem dicken, blauen Reisekatalog, darunter «Zeit für Gefühle». Was dann folgt, ist eine Hypnosebehandlung des Fernwehs, Werbelyrik vom Feinsten: «Spür das Fieber in dir, komm in den Club. Entdecke neue Leidenschaften, sei einfach du selbst. Lass dein Herz entscheiden, du wirst Feuer fangen.» So geht es weiter im O-Ton: Du, Held auf zwei Brettern, das wird deine Zeit, lass dich vom Glück berühren. Die kulinarischen Versuchungen prickeln, explodieren am Gaumen usw. usf. Zeit für das Wesentliche, wenn man nur wüsste, was das wäre. Je schamloser geschmeichelt, desto besser verkauft. Defoes Robinson war bekanntlich freiwillig auf seiner Insel, Annullationsversicherung inklusive. Natürlich gibt es auch intelligentere Werbung, witzig, frech, sprachspielerisch und unterhaltend. Was bleibt, ist eine Verkaufslogik, die unterschiedliche Geldbeutel bedient.

Der niederländische Arzt Bernard de Mandeville (1670-1733) gehört mit seiner hellsichtigen Satire «Fable of the Bees or Private Vices, Public Benefits» zu den Gründervätern der modernen Ökonomie. Seine Bienenfabel preist den menschlichen Eigennutz als Quelle des Wohlstandes: «What we call evil in this world, Moral as well as Natural, is the Great Principle that makes us Sociable Creatures.» Der Drang nach Mehr, Gier, Habsucht, Neid, Schmeichelei und Ehrgeiz sind die Antriebskräfte der Wirtschaft, das Laster ist die Quelle allen Allgemeinwohls. Ökonomen wie Adam Smith und John Maynard Keynes werden seine Einsichten verfeinern, Karl Marx seine Erkenntnis hervorheben, dass die Prosperität auf der billigen Arbeit des Proletariats beruht. Die Ansichten des Nerven- und Magenspezialisten wurden kontrovers aufgenommen. Doch schon zu Lebzeiten erreichte Mandevilles Werk mehrere Auflagen. Die Einschätzung starker Emotionen veränderte sich allmählich ins Gegenteil. Einst verurteilt und durch Tugenden oder Strafen in Schach gehalten, wurden die zu Leidenschaften gesteigerten Gefühle aufgewertet. Von Morallehren befreit, machte die Aufklärung die Passion zur Lebenskraft, zur Triebfeder grosser Leistungen, zum Lebensprinzip der Nationen und Individuen. Wie der losbrechende Kapitalismus setzt die neue Gefühlsökonomie ungeheure Kräfte frei. Kant bleibt misstrauisch. Er nennt die Leidenschaften «Krebsschäden für die reine praktische Vernunft und mehrenteile unheilbar: weil der Kranke nicht will geheilt sein.» Nietzsche argumentiert dagegen: «Nicht eure Sünde schreit gen Him- mel, euer Geiz selbst in der Sünde schreit gen Himmel. Wo ist doch der Blitz, der euch mit seiner Zunge lecke? Wo ist der Wahnsinn, mit dem ihr geimpft werden müsst?»

Mit dem Wahnsinn sind wir vertraut, doch was hat das mit dem Reisen zu tun? Die Tourismusbranche kanalisiert die Sehnsüchte, offensichtlicher als jede andere Konsumsparte. Sie verwaltet effizient die Fluchtgelüste der Arbeitsbienen. Wer nicht im Extremsport sein Adrenalin sucht, unternimmt eine Pauschalreise ins Andersland. Das in Preiskategorien organisierte Abenteuer für jede Altersklasse garantiert Vieles, selten nur eine Entdeckung. Last-Minute-Reisen und andere Schnäppchen bestätigen Mandevilles Beitrag zur Lage der Unterprivilegierten. Marco Polo war Jahre auf eigenes Risiko unterwegs, unsere Bildungsreise dauert zwei Wochen. Und was sich gerade in der Mongolei zuträgt, kennen wir schon vom Fernseher. Zur kollektiven Bewirtschaftung der Gefühle gibt es Alternativen. Wem Animation und Event nicht genügen, der bleibe zu Hause oder reise auf eigene Gefahr, abseits der Trampelpfade. Reisemuffel sind entweder besonders fantasievoll oder das Gegenteil davon, lasterhaft faul oder tugendhaft weise. Sie haben die Ökologie auf ihrer Seite, ein starkes Argument. Für Leser gibt es die Reiseliteratur. Da geht einer zu Fuss und ohne Geld von Paris nach Berlin [1], ein anderer bricht dort auf und läuft bis Moskau [2]. Beide schreiben ein Buch, dazu war die Show gedacht. Reisen ist am schönsten, wenn man nicht kann. Etwa weil man in einem Land lebt, wo das nicht ging, wie Judith Schalansky in der DDR. Sie schrieb einen «Atlas der abgelegenen Inseln» [3]. «Fünfzig Inseln, auf denen ich nie war und niemals sein werde». Das Buch wurde 2009 zum schönsten deutschen Buch des Jahres gekürt. Zu jeder Abbildung einer Insel gehört eine kurze Geschichte, die meistens skurril und tragisch verläuft. Die Autorin entwirft kein romantisches Gegenbild zum Alltag. Jedes Eiland ist eine Fussnote zum Festland, oft von Kartographen übergangen. Einsam und verloren liegen diese meist kargen Orte, mehr Gefängnis als Erholungsort, für die wenigsten eine Schatzinsel. Mal richtig reisen, mal nur mit der Fingerkuppe auf der Landkarte. So haushalten, dass man gar nicht erst reif für die Insel wird? Die Sehnsucht war ein Teil des antiken Gefühlsrepertoires. Zum guten Leben gehörte auch eine Diätetik der Affekte. Der Arzt Mandeville hätte dem sicher beigepflichtet. 